\title{
Intoxicação experimental por Metternichia princeps (Solanaceae) em ovinos e bovinos ${ }^{1}$
}

\author{
Saulo A. Caldas ${ }^{2}$, Marilene de Farias Brito ${ }^{3}$, Juliana da Silva Prado ${ }^{4}$, Elise Miyuki \\ Yamasaki $^{4}$, Luciane Veronezi ${ }^{5}$, Fernanda Jönck ${ }^{5}$, Diogo dos Santos Maia ${ }^{6}$ \\ e Carlos Hubinger Tokarnia ${ }^{7 *}$
}

\begin{abstract}
Caldas A.A., Brito M.F., Prado J.S., Yamasaki E.M., Veronezi L., Jönck F., Maia D.S. \& Tokarnia C.H. 2012. [Experimental poisoning by Metternichia princeps (Solanaceae) in sheep and cattle.] Intoxicação experimental por Metternichia princeps (Solanaceae) em bovinos e ovinos. Pesquisa Veterinária Brasileira 32(10):1023-1029. Projeto Sanidade Animal Embrapa/UFRRJ, Seropédica, RJ 23890-000, Brazil. E-mail: tokarnia@ufrrj.br

Metternichia princeps, had been shown responsible for deaths of goats on a farm in Itaguaí county, state of Rio de Janeiro. Its toxicity was proved by experiments in goats and rabbits. In the present study sheep and cattle were shown also to be sensitive to poisoning by the leaves of M. princeps. The lowest lethal dose was $10 \mathrm{~g} / \mathrm{kg}$ for sheep, and $20 \mathrm{~g} / \mathrm{kg}$ for cattle. The clinical signs of the poisoning were little specific. The course of the experimental poisoning varied from $6 \mathrm{~h} 4 \mathrm{~min}$ to $99 \mathrm{~h}$ in sheep, and from $4 \mathrm{~h} 46 \mathrm{~min}$ to $75 \mathrm{~h} 30 \mathrm{~min}$ in cattle. The most important findings at postmortem examination in the experimental animals were excessive cavitary fluid accumulation and edemas, especially of the perirenal tissue (present in 4 of 6 sheep, and in 2 of 3 cattle). The most important microscopic lesion was coagulative necrosis of the uriniferous tubules in the renal cortex (found in 8 of 9 cattle, except in one in which the course of poisoning was very short, but in all 6 sheep). In 5 of 6 sheep a diffuse swelling of the hepatocytes was found, a change not seen in cattle.
\end{abstract}

INDEX TERMS: Poisonous plants, Metternichia princeps, Solanaceae, plant poisoning, cattle, sheep.

RESUMO.- Metternichia princeps foi responsabilizada pelas mortes que ocorreram em caprinos em uma criação de cabras no município de Itaguaí, estado do Rio de Janeiro; comprovou-se sua toxidez em caprinos e em coelhos. No presente estudo os ovinos e bovinos também foram sensíveis à intoxicação pelas folhas de $M$. princeps. A menor dose que causou a morte dos ovinos foi $10 \mathrm{~g} / \mathrm{kg}$ e dos bovinos foi $20 \mathrm{~g} / \mathrm{kg}$. A sintomatologia nas duas espécies foi pouco específica; a evolução da intoxicação experimental nos ovinos

\footnotetext{
${ }^{1}$ Recebido em 8 de junho de 2012.

Aceito para publicação em 17 de julho de 2012.

${ }^{2}$ Departamento de Medicina e Cirurgia Veterinária, Instituto de Veterinária, Universidade Federal Rural do Rio de Janeiro (UFRRJ), BR $465 \mathrm{Km}$ 7, Seropédica, RJ 23890-000, Brasil.

${ }^{3}$ Departamento de Epidemiologia e Saúde Pública, Instituto de Veterinária, UFRRJ, Seropédica, RJ.

${ }^{4}$ Discentes do Curso de Pós-Graduação em Ciências Veterinárias, UFRRJ, Seropédica, RJ.

${ }^{5}$ Discentes do Curso de Pós-Graduação em Medicina Veterinária, UFRRJ, Seropédica, RJ.

${ }^{6}$ Médico Veterinário, autônomo, Rio de Janeiro, RJ, Brasil.

${ }^{7}$ Departamento de Nutrição Animal e Pastagem, Instituto de Zootecnia, UFRRJ, Seropédica, RJ. *Autor para correspondência: tokarnia@ufrrj.br
}

variou de $6 \mathrm{~h} 4 \mathrm{~min}$ a $99 \mathrm{~h}$ e nos bovinos foi de $4 \mathrm{~h} 46 \mathrm{~min}$ a $75 \mathrm{~h} 30 \mathrm{~min}$. Nos achados de necropsia destacaram-se derrames cavitários e edemas, especialmente no tecido perirrenal (presente em 4 de 6 dos ovinos e em 2 de 3 bovinos). Muito características foram as alterações renais, sob forma de necrose coagulativa dos túbulos uriníferos no córtex renal (encontrada em 8 dos 9 bovinos, exceto em um, no qual a evolução da intoxicação foi muito breve, e em todos os 6 ovinos). Em 5 dos 6 ovinos foi constatada, adicionalmente, lesão hepática sob forma de uma tumefação difusa de todos os hepatócitos, alteração que não foi verificada nos bovinos.

TERMOS DE INDEXAÇÃO: Plantas tóxicas, Metternichia princeps, Solanaceae, intoxicação por planta, bovinos, ovinos.

\section{INTRODUÇÃO}

Em um estabelecimento no município de Itaguaí, RJ, ocorria uma doença renal de evolução aguda a subaguda com alto índice de letalidade em caprinos. Através da experimentação em caprinos se comprovou que esta doença era devido à ingestão das folhas de Metternichia princeps, árvore arbustiva da família Solanaceae, com nome popular 
de "jasmim-do-morro" "café-do-mato" e "trombeteira". No quadro clínico-patológico desta doença em caprinos, tanto natural como experimental, de evolução aguda a subaguda, inicialmente se observa inapetência, adipsia, apatia e relutância ao movimento. Em seguida os animais entram em decúbito esternal e ao serem colocados em estação, mantêm os membros anteriores flexionados, apoiam apenas os posteriores no chão até evoluir para flexão dos quatro membros e segue-se o decúbito lateral. À necropsia destacam-se o edema de tecido adiposo perirrenal, rins pálidos e, ao corte, com estriação esbranquiçada desde o córtex até a região medular. À histopatologia verifica-se acentuada necrose coagulativa das células epiteliais dos túbulos uriníferos. A menor dose letal foi 2,5g/kg. (Caldas et al. 2011, Prado et al. 2012)

Em seguida foram realizados experimentos em coelhos com o fim de se verificar se estes servem como animais experimentais de pequeno porte. Nesta espécie animal, em que a intoxicação teve evolução superaguda a aguda, os coelhos tornaram-se apáticos, com mucosas pálidas a cianóticas e orelhas frias, até que subitamente se debatiam na gaiola, faziam movimentos de pedalagem, vocalizavam, apresentavam acentuada dispneia e morriam. À necropsia, o fígado apresentava-se com evidenciação da lobulação; os demais órgãos estavam congestos e os vasos sanguíneos ingurgitados. À histopatologia, as lesões mais relevantes foram, no fígado, intensa congestão, especialmente centrolobular, tumefação acentuada dos hepatócitos e focos de necrose incipiente de hepatócitos; no coração, além de congestão, fibras cardíacas com aumento de eosinofilia, com picnose nuclear e fibras cardíacas vacuolizadas. No rim havia leve a moderada congestão e tumefação de células epiteliais. Esses experimentos demonstraram que o coelho é sensível à intoxicação pelas folhas frescas e dessecadas de M. princeps, mas o quadro clínico-patológico é bem diferente do observado em caprinos. Sugeriu-se que o princípio tóxico de M. princeps responsável pelo quadro clínico-patológico da intoxicação em coelhos não seja o mesmo princípio responsável pela intoxicação nos caprinos, ou que os coelhos reagem de maneira diferente dos caprinos; nos coelhos predominam alterações cardíacas e hepáticas enquanto que em caprinos as lesões são renais. (Maran et al. 2012)

0 presente estudo foi realizado para verificar se ovinos e bovinos são sensíveis a intoxicação por M. princeps, qual a sua sensibilidade e qual é o quadro clínico-patológico.

\section{MATERIAL E MÉTODOS}

Foram usados 8 ovinos jovens, com peso entre 12,5 e 23,5 kg, e 8 bovinos jovens, com peso entre 90 e $147 \mathrm{~kg}$. Os animais foram mantidos em boxes individuais, recebiam capim picado e pequena quantidade de ração. Antes dos experimentos eram vermifugados.

A maioria dos animais recebeu quantidades pré-determinadas de Metternichia princeps; a planta era colocada na boca dos animais, que a então mastigavam e engoliam. Somente dois ovinos (5781 e 5782) comeram espontaneamente pequena parte da planta colocada no cocho.

A planta era coletada no pasto da propriedade onde ocorreu a doença, no município de Itaguai/RJ, sempre no dia da administração, com exceção dos experimentos que se estenderam por mais de um dia, em que era guardada em geladeira.
Os animais eram examinados clinicamente antes do início do experimento e após a administração da planta pelo menos duas vezes ao dia; quando adoeceram foram assistidos continuamente com frequentes exames. Esses incluíram, além das observações gerais do estado do animal, em tomada da temperatura, determinações das frequências cardíaca e respiratória e da atividade do rúmen.

Sangue foi coletado da veia jugular para realização de provas de função hepática e renal, e dosagens de cálcio, sódio e potássio sérico. Esses exames foram realizados na Universidade Federal do Pará, Campus Castanhal, PA.

No caso de morte, fazia-se imediatamente a necropsia com coleta de material para exames histopatológicos.

\section{RESULTADOS}

Nos Quadros 1 e 2 constam os delineamentos dos experimentos, respectivamente dos ovinos e dos bovinos.

Em relação aos ovinos, verificou-se que a dose de $20 \mathrm{~g} / \mathrm{kg}$ administrada em dois dias causou a morte dos dois ovinos, as de $10 \mathrm{~g} / \mathrm{kg}$ administradas de uma só vez causaram a morte dos 3 ovinos, e a de $5 \mathrm{~g} / \mathrm{kg}$ causou a morte de um de 3 ovinos. Os primeiros sinais clínicos foram observados entre aproximadamente 20 a 30 horas após o início da administração da planta. A evolução da doença letal foi de $6 \mathrm{~h} 5 \mathrm{~min}$ a $99 \mathrm{~h} 7 \mathrm{~min}$. Em todos os ovinos que morreram foram observados principalmente apatia e anorexia. 0 Ovino 5783 ainda mostrou andar cambaleante. Havia redução na quantidade e intensidade dos movimentos do rúmen, até atonia. Os animais acabaram assumindo o decúbito esterno-abdominal, depois lateral e seguia-se a morte.

Nos exames bioquímicos do sangue dos ovinos não foram observadas alterações na atividade de ALT e AST indicativas de dano hepatocelular, decorrente da ingestão da planta. A concentração de ureia esteve aumentada em todos os animais, em alguns associada ao aumento da concentração de creatinina (Ovinos 5785 e 5787). A atividade da CK esteve aumentada em todos os animais, enquanto que a atividade da LDH não mostrou alteração. As concentrações de cálcio tenderam a valores abaixo da normalidade (Ovinos 5785, 5787 e 5786), e as concentrações de fósforo variaram discretamente (hipofosfatemia nos ovinos $5783,5784,5785$ e 5787; hiperfosfatemia no Ovino 5786). As concentrações de sódio e potássio tenderam à normalidade, ou apresentaram discretas variações (hipernatremia nos ovinos 5784, 5785, 5786 e 5787). (Quadro 3)

Os achados de necropsia nos ovinos foram presença de líquido citrino nas cavidades epicárdica (Ovinos 5781, 5783) e abdominal (Ovino 5781), edema perirrenal (Ovinos 5781, 5783, 5785, 5787) (Fig.1-2), edema do mesentério envolvendo diversos órgãos (Ovinos 5783, 5785, 57866 ), líquido espumoso na traqueia (ovinos 5782, 5786, 5787), fígado com evidenciação da lobulação (Ovino 5781) e fígado pálido (Ovinos 5782, 5787).

Em todos os ovinos experimentais as alterações histológicas afetavam principalmente o rim, sob forma de acentuada necrose coagulativa dos túbulos renais no córtex, pela qual as células epiteliais transformavam-se em massas eosinofílicas amorfas, delimitada externamente pela membrana basal dos túbulos (Fig.3-4), precipitados 

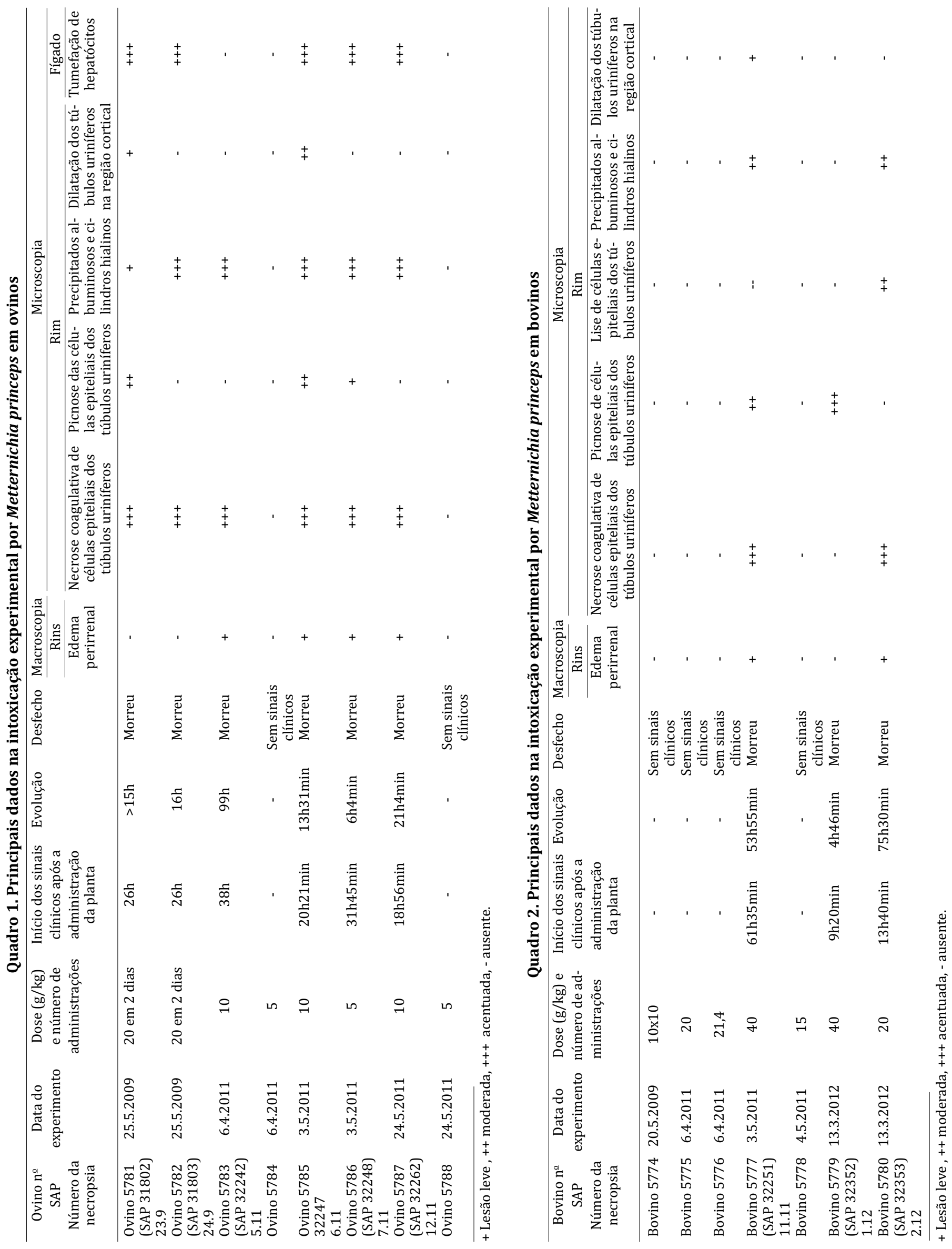
Quadro 3. Bioquímica sanguínea na intoxicação experimental por Metternichia princeps em ovinos

\begin{tabular}{lccccccccccccc}
\hline $\begin{array}{c}\text { Parâmetros } \\
\text { avaliados }\end{array}$ & \multicolumn{4}{c}{$\begin{array}{c}\text { Ovino 5783 } \\
\text { (SAP 32242) }\end{array}$} & & Ovino 5784 & \multicolumn{2}{c}{$\begin{array}{c}\text { Ovino 5785 } \\
\text { (SAP 32247) }\end{array}$} & $\begin{array}{c}\text { Ovino 5786 } \\
\text { (SAP 32248) }\end{array}$ & $\begin{array}{c}\text { Ovino 5787 } \\
\text { (SAP 32262) }\end{array}$ & Ovino 5788 \\
ALT & T0 & T1 & T2 & T3 & T0 & T1 & T0 & T1 & T0 & T1 & T0 & T1 & T0 \\
AST & 40 & 37 & 33 & 28 & 27 & 20 & 33 & 18 & 43 & 16 & 32 & 27 & 37 \\
Ureia & 69 & 63 & 89 & 76 & 60 & 45 & 89 & 30 & 46 & 76 & 86 & 120 & 89 \\
Creatinina & 1.4 & 40 & 40 & 33 & 60 & 48 & 102 & 38 & 54 & 28 & 108 & 111 & 36 \\
CK & 76 & 226 & 0 & 1.1 & 2.0 & 1.6 & 3.4 & 1.0 & 1.8 & 0.9 & 3.6 & 3.7 & 1.2 \\
DHL & 289 & 290 & 220 & 190 & 220 & 366 & 136 & 306 & 240 & 0 & 140 & 0 & 173 \\
Ca & 11.8 & 12.0 & 10.4 & 9.9 & 11.8 & 9.3 & 9.0 & 10.2 & 10.2 & 10.6 & 10.1 & 9.8 & 11.6 \\
P & 5.9 & 7.0 & 4.5 & 8.1 & 5.8 & 4.5 & 5.0 & 4.7 & 5.7 & 5.0 & 3.9 & 5.6 & 6.6 \\
Na & 148 & 136 & 152 & 140 & 134 & 172 & 160 & 160 & 138 & 180 & 162 & 170 & 140 \\
K & 4.0 & 3.8 & 4.2 & 3.0 & 4.0 & 3.3 & 4.0 & 5.3 & 4.6 & 5.0 & 4.8 & 5.1 & 3.8
\end{tabular}

T0 = coleta de sangue antes da administração da planta; T1, T2 e T3 = coletas de sangue durante a evolução da intoxicação.
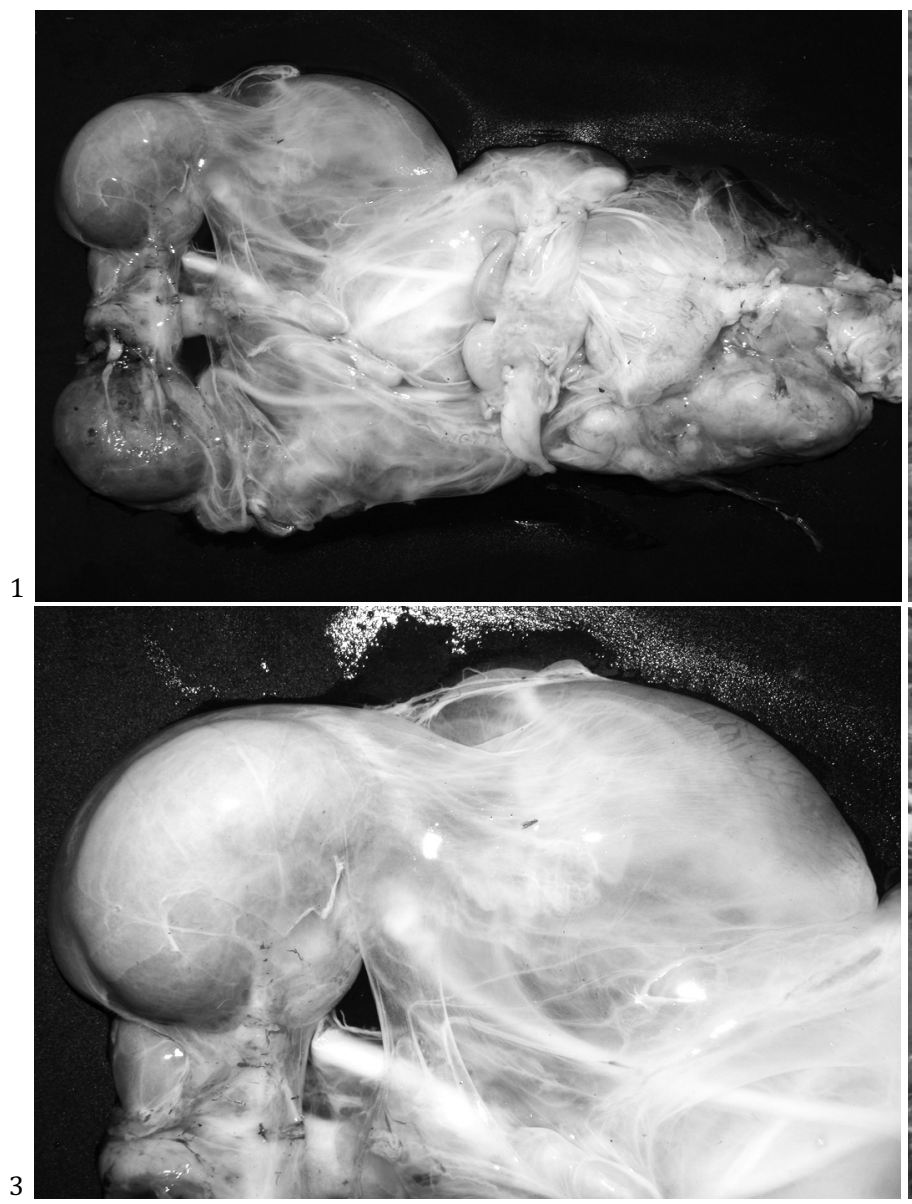

Fig.1. Edema perirrenal na intoxicação experimental $(10 \mathrm{~g} / \mathrm{kg})$ por Metternichia princeps no Ovino 5783 (SAP 32242).

Fig.3. Necrose coagulativa de grande parte dos túbulos uriníferos do córtex renal na intoxicação experimental $(20 \mathrm{~g} / \mathrm{kg}$ em 2 dias) por Metternichia princeps no Ovino 5781 (SAP 31802). HE, obj.6,3x.

albuminosos e cilindros hialinos na medula do rim, e em menor grau, dilatação de túbulos uriníferos no córtex. Ainda havia, em todos os ovinos, alterações no fígado, em que os hepatócitos apresentaram-se, de maneira difusa, com aspecto de células vegetais devido à tumefação (Fig.5-6).

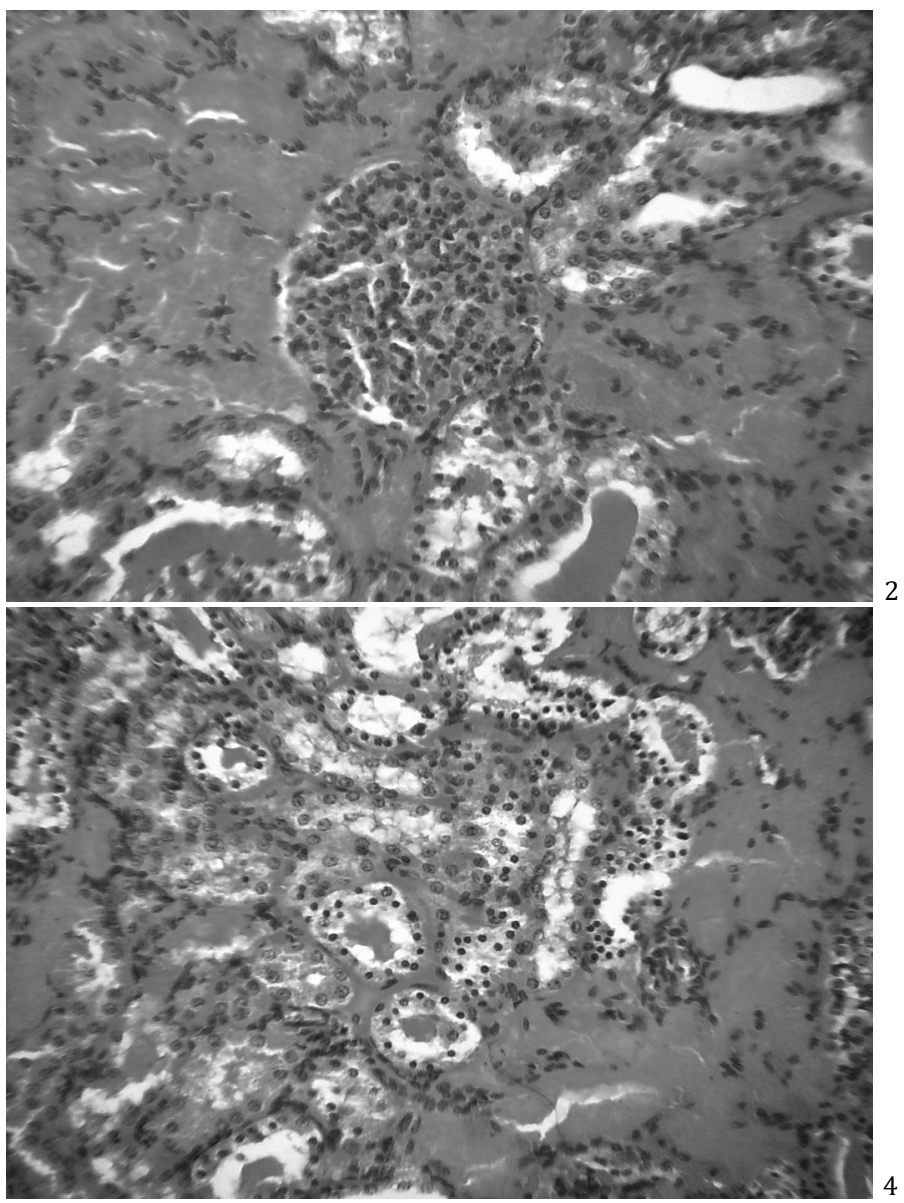

Fig.2. Vista aproximada do edema perirrenal na intoxicação experimental $(10 \mathrm{~g} / \mathrm{kg})$ por Metternichia princeps no Ovino 5783 (SAP 32242).

Fig.4. Necrose coagulativa e picnose das células epiteliais dos túbulos uriníferos do córtex renal na intoxicação experimental (20g/kg em 2 dias) por Metternichia princeps no Ovino 5781 (SAP 31802). HE, obj.6,3x.

Ainda havia edema na submucosa ou na própria no trato digestório.

Em relação aos bovinos verificou-se que a dose de $40 \mathrm{~g} / \mathrm{kg}$ causou a morte dos dois bovinos, a dose de $20 \mathrm{~g} / \mathrm{kg}$ foi letal em um de três bovinos e a dose de $15 \mathrm{~g} / \mathrm{kg}$ não causou morte. Do- 


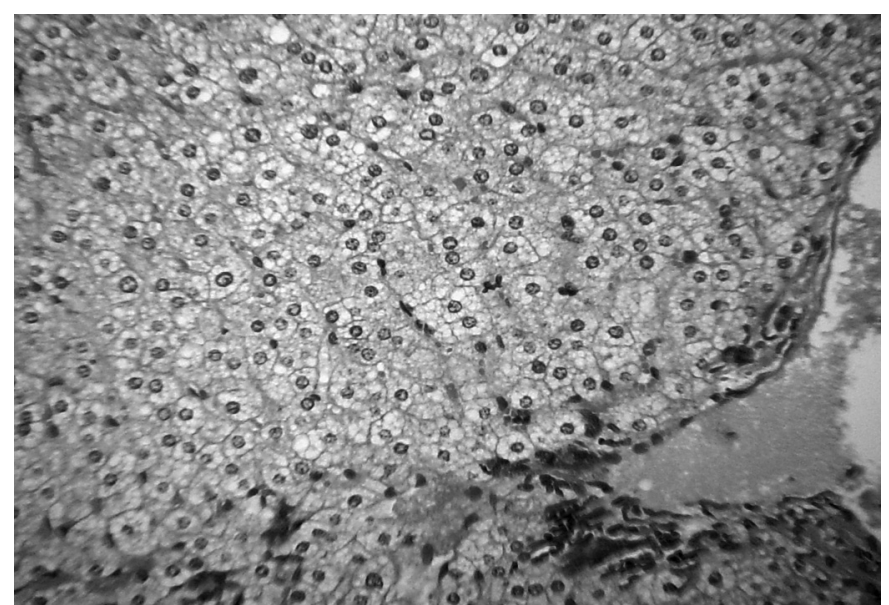

Fig.5. Tumefação difusa dos hepatócitos na intoxicação experimental (20g/kg em 2 dias) por Metternichia princeps no Ovino 5781 (SAP 31802). HE, obj.16x.

ses de $10 \mathrm{~g} / \mathrm{kg} /$ dia durante 10 dias também não causaram sinais clínicos de intoxicação. Os primeiros sinais clínicos foram observados entre aproximadamente 9 e 61 horas após o início da administração da planta. A evolução da doença letal foi de $4 \mathrm{~h} 46 \mathrm{~min}$ a $75 \mathrm{~h} 30 \mathrm{~min}$. Os bovinos que morreram mostraram inapetência até anorexia, diminuição da frequência e intensidade dos movimentos ruminais até atonia, andar incoordenado (Ovinos 5784, 5787), decúbito esternal com a cabeça encostada no flanco, respiração lenta e profunda, decúbito lateral e morte.

Nos exames bioquímicos do sangue dos bovinos a atividade de ALT e AST estava próximo da normalidade em todos os animais com exceção de um (Bovino 5777). As concentrações de ureia e creatinina também demonstraram comportamento semelhante, e em alguns animais houve aumento discreto da concentração de ureia, não associado ao aumento da concentração de creatinina (Bovinos 5775 e 5778). Na atividade das enzimas CK e LDH houve tendência a valores aumentados em todos os animais. A concentração de fósforo ficou próximo da normalidade em todos os animais, com exceção de um (Bovino 5775 - T1), enquanto que a concentração de cálcio apresentou discreta diminui-

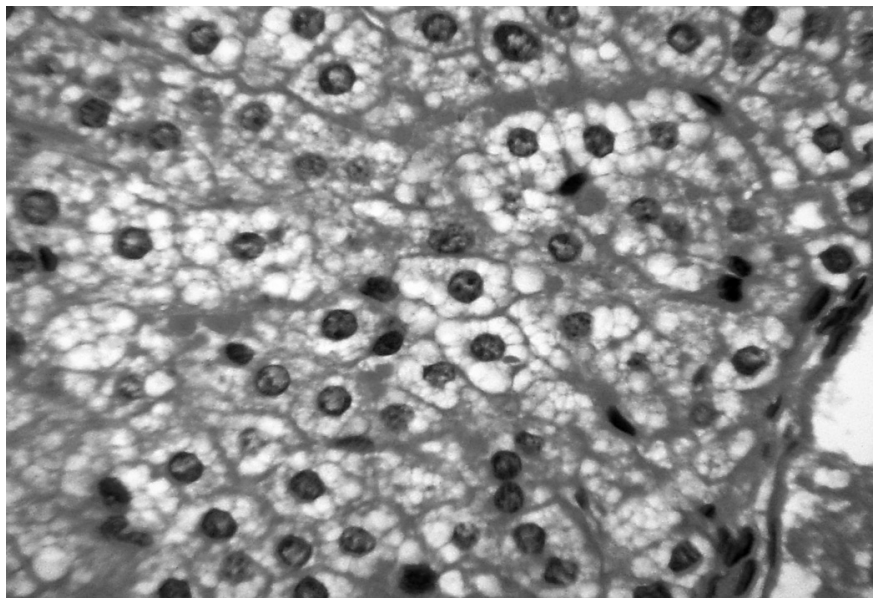

Fig.6. Vista aproximada da tumefação difusa dos hepatócitos na intoxicação experimental (20g/kg em 2 dias) por Metternichia princeps no Ovino 5781 (SAP 31802). HE, obj.25x.
Quadro 4. Bioquímica sanguínea na intoxicação experimental por Metternichia princeps em bovinos

\begin{tabular}{lccccccc}
\hline $\begin{array}{c}\text { Parâmetros } \\
\text { avaliados }\end{array}$ & \multicolumn{2}{l}{ Bovino 5775 } & \multicolumn{3}{c}{ Bovino 5776 } & \multicolumn{3}{c}{$\begin{array}{c}\text { Bovino 5777 } \\
\text { (SAP 32251) }\end{array}$} & Bovino 5778 \\
\hline & & & & & \\
ALT & 20 & 20 & 13 & 13 & 98 & 60 & 13 \\
AST & 40 & 46 & 56 & 63 & 310 & 180 & 56 \\
Ureia & 27 & 35 & 27 & 76 & 35 & 152 & 27 \\
Creatinina & 0.6 & 1.2 & 0.9 & 2.3 & 0.7 & 3.8 & 0.9 \\
CK & 186 & 226 & 380 & 206 & 336 & 130 & 380 \\
DHL & 1.570 & 1.473 & 1.514 & 1.489 & 1.862 & 2.064 & 1.514 \\
Ca & 6.2 & 7.2 & 6.8 & 8.0 & 7.2 & 7.2 & 6.8 \\
P & 6.1 & 4.0 & 7.4 & 5.9 & 7.5 & 5.7 & 7.4 \\
Na & 130 & 138 & 136 & 124 & 138 & 136 & 136 \\
K & 4.8 & 5 & 5.8 & 4.4 & 4.5 & 4.2 & 5.8
\end{tabular}

T0 = coleta de sangue antes da administração da planta; $\mathrm{T} 1$ = coleta de sangue durante a evolução da intoxicação.

ção em todos os animais. As concentrações de sódio e de potássio também estiveram próximas da normalidade, ou apresentaram discretas alterações. (Quadro 4)

Os achados de necropsia nos bovinos foram presença de líquido citrino no saco pericárdico (Bovinos 5777, 5780), e edema perirrenal (Fig.7-8) (Bovinos 5777, 5780).

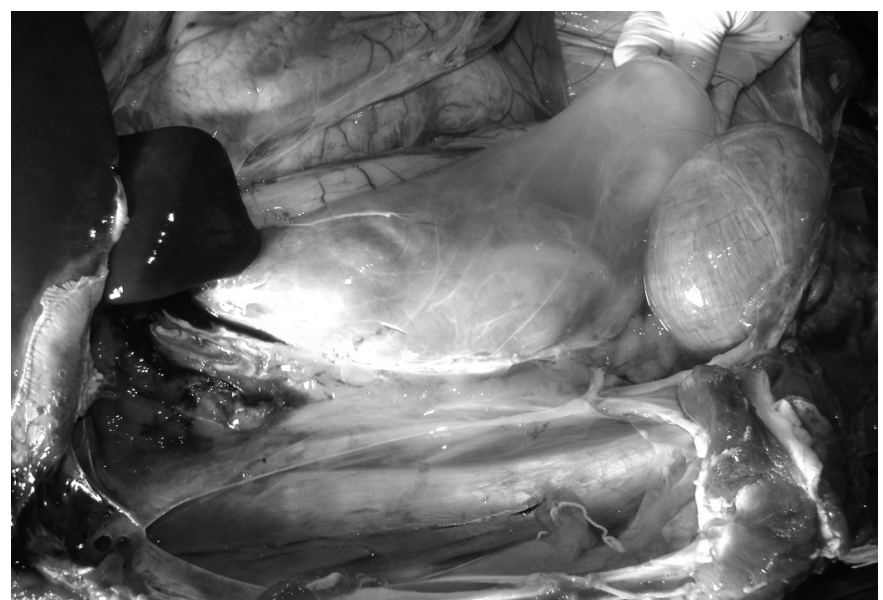

Fig.7. Edema perirrenal na intoxicação experimental (20g/kg) por Metternichia princeps no Bovino 5780 (SAP 32353).

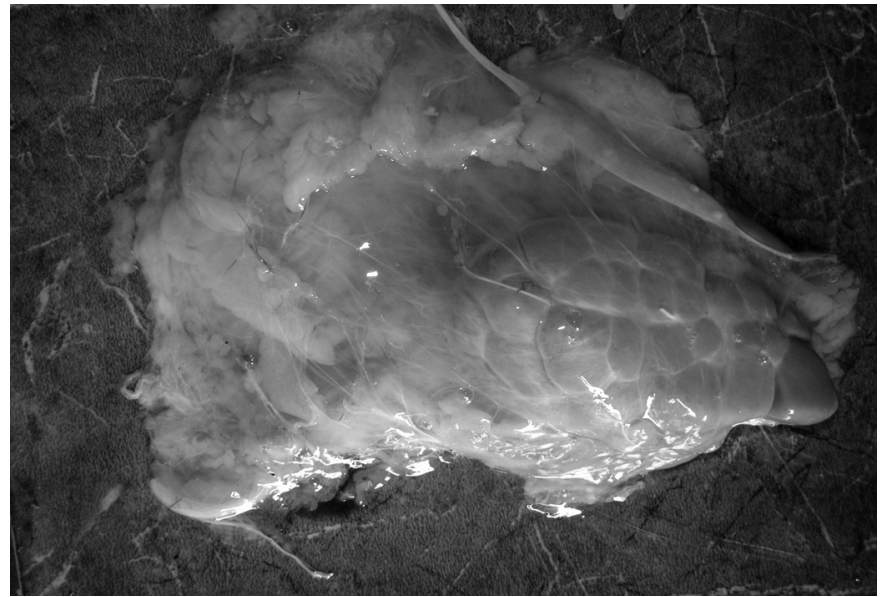

Fig.8. Vista aproximada do edema perirrenal na intoxicação experimental $(20 \mathrm{~g} / \mathrm{kg})$ por Metternichia princeps no Bovino 5780 (SAP 32353). 


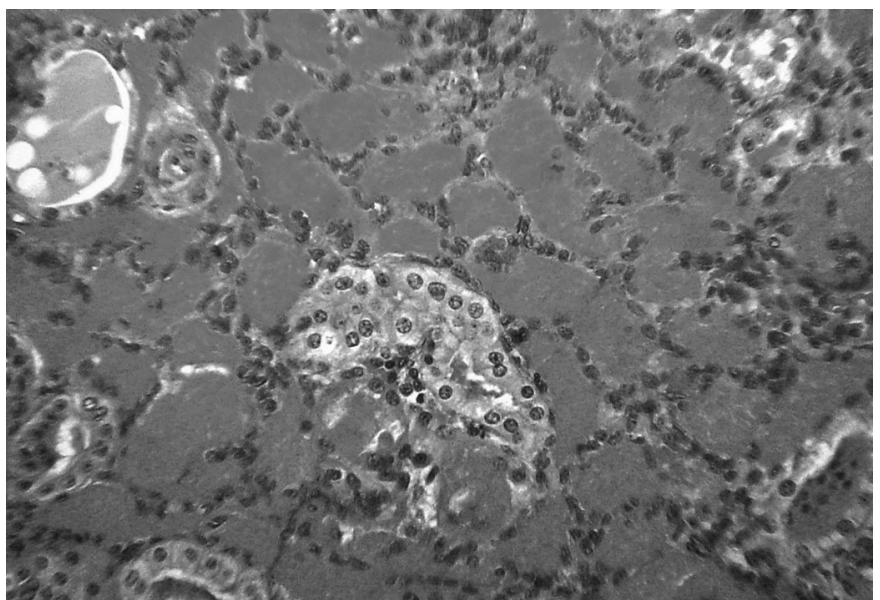

Fig.9. Necrose coagulativa e dilatação de túbulos uriníferos do córtex renal na intoxicação experimental $(40 \mathrm{~g} / \mathrm{kg})$ por Metternichia princeps no Bovino 5777 (SAP 32251). HE, obj.16x.

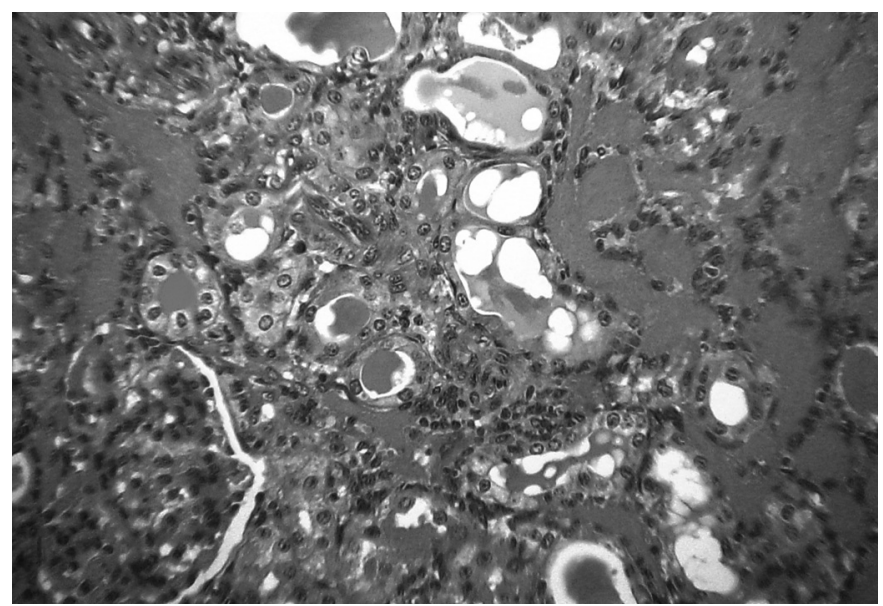

Fig.10. Necrose coagulativa de túbulos uriníferos do córtex renal na intoxicação experimental $(40 \mathrm{~g} / \mathrm{kg})$ por Metternichia princeps no Bovino 5777 (SAP 32251). HE, obj.16x.

Alterações histológicas foram verificadas principalmente no rim, sob forma de necrose coagulativa dos túbulos uriníferos no córtex (Bovinos 5777, 5780) (Fig.9-10), semelhante à vista nos ovinos; em outros túbulos as células epiteliais mostraram sinais de necrose sob forma de picnose de seus núcleos ou através de lise em menor ou maior grau. Ainda foram vistos precipitados albuminosos e cilindros hialinos, principalmente na medula do rim. No Bovino 5779 , se observou no rim somente condensação da cromatina dos núcleos (picnose) de grande parte dos túbulos uriníferos no córtex. No Bovino 5777 ainda foi observado edema na própria e na submucosa de diversos segmentos do trato digestório. No Bovino 5780 foi visto dissociação dos cordões hepáticos.

\section{DISCUSSÃO E CONCLUSÕES}

No presente estudo os ovinos e bovinos também foram sensíveis à intoxicação pelas folhas de Metternichia princeps, porém as doses letais foram mais elevadas do que aquelas necessárias para caprinos. Para caprinos a menor dose que causou a morte, foi 2,5gkg (Prado et al. 2012), já para ovinos foi $10 \mathrm{~g} / \mathrm{kg}$ e para bovinos $20 \mathrm{~g} / \mathrm{kg}$. A sintomatologia nas três espécies foi pouco específica. A evolução da intoxicação experimental foi muito variável em cada uma das três espécies de ruminantes, de poucas horas a dias. Nos achados de necropsia destacaram-se derrames cavitários, e edemas, especialmente no tecido perirrenal (presente em 4 de 6 dos ovinos e em 2 de 3 bovinos, e, em 3 de 9 caprinos experimentais). Nos casos naturais o edema perirrenal só foi observado em 1 de 10 caprinos. Muito características foram as alterações microscópicas renais. Como nos caprinos, também nos ovinos e bovinos a alteração mais importante foi a necrose coagulativa dos túbulos uriníferos no córtex renal. (foi encontrado em todos bovinos, exceto Bovino 5779, em que a evolução da intoxicação foi muito breve, em todos os ovinos e em 8 de 9 caprinos experimentais). Nos casos naturais a necrose coagulativa de túbulos renais foi observada em 4 de 10 caprinos. Nos ovinos foi constatada adicionalmente lesão hepática, sob forma de uma tumefação difusa de todos hepatócitos (em todos menos no Ovino 5783), alteração que não foi verificada nos bovinos. Esta tumefação dos hepatócitos foi observada em todos os coelhos experimentais (Maran et al 2012). Nos caprinos esta tumefação dos hepatócitos foi observada em 5 dos 10 casos naturais e em 6 dos 9 casos experimentais da intoxicação por M. princeps.

No que diz respeito à bioquímica sérica, nos ovinos 5785 e 5787 a concentração aumentada de ureia e creatinina é sugestiva de insuficiência renal. 0 aumento da concentração de ureia, isoladamente, pode estar relacionado a várias causas pré-renais (Kerr 2003). 0 aumento da atividade da CK é consistente com lesão muscular (Thrall 2006). Porém, muitas amostras apresentaram-se hemolisadas e deste modo, a atividade de CK pode apresentar-se falsamente elevada. Hipocalcemia pode estar relacionada à hipoalbuminemia/hipoproteinemia ou nefropatia com perda proteica (Stockham \& Scott 2011). As variações na concentração de fósforo não foram associadas ao aumento da concentração de ureia e creatinina, o que permite sugerir que não estão relacionadas a nefropatia. A hipernatremia no Ovino 5787 pode ser devida à insuficiência renal, entretanto, as alterações observadas não ocorreram sempre simultaneamente com as evidências de nefropatia, o que indica que o equilíbrio eletrolítico não foi alterado exclusivamente por insuficiência renal.

Quanto à bioquímica sérica dos bovinos, o aumento da atividade de AST (Bovino 5777) pode estar relacionado a dano hepatocelular leve (Gonzáles \& Silva 2006), considerando-se que no momento em que a atividade da LDH aumenta, a atividade da AST diminui. Associados, os aumentos das concentrações de ureia e creatinina são consistentes com insuficiência renal. Aumento da concentração de ureia pode estar relacionado a causas pré-renais (Kerr 2003) e o aumento da atividade de CK é consistente com lesão muscular (Thrall 2006). A elevação da atividade de LDH com simultânea redução da atividade de CK (Bovinos 5777 e 5776) ou com retorno à normalidade aponta para a hipótese de lesão muscular. Hipocalcemia pode estar relacionada à hipoalbuminemia/hipoproteinemia ou nefropatia com perda proteica (Stockham \& Scott 2011). A 
hipofosfatemia observada no Bovino 5775 - T1, não tem relação com comprometimento da função renal. As alterações observadas nas concentrações de sódio e potássio não ocorreram simultaneamente com as evidências de nefropatia, o que indica que o equilíbrio eletrolítico não foi significativamente alterado.

Agradecimentos.- Ao Prof. José Diomedes Barbosa, da Universidade Federal do Pará, Campus Castanhal, PA, pela realização dos exames bioquímicos do sangue.

\section{REFERÊNCIAS}

Caldas S.A., Prado J.S., Costa S.Z.R., Peixoto T.C., Brito M.F. \& Tokarnia C.H. 2011. Intoxicação natural por Metternichia princeps (Solanaceae) em caprinos. XV Enapave, Goiânia, GO. (Resumo)

Gonzáles F.H.D. \& Silva S.C. 2006. Perfil bioquímico sanguíneo, p.313-358.
In: Ibid. (Eds), Introdução à Bioquímica Clínica Veterinária. Editora da UFRGS, Porto Alegre.

Kerr M.G. 2003. Avaliação com base em órgãos individuais, p.239-249. In: Ibid. (Ed.), Exames Laboratoriais em Medicina Veterinária: bioquímica clínica e hematologia. Roca, São Paulo.

Maran N.B., Caldas S.A., Prado J.S., Gomes A.D., Tokarnia C.H. \& Brito M.F. 2012. Intoxicação experimental por Metternichia princeps (Solanaceae) em coelhos. Pesq. Vet. Bras. 32(9):872-880.

Prado J.S., Brito M.B., Caldas S.A., Yamasaki E.M., Barbosa J.D., Maia D.S. \& Tokarnia C.H. 2012. Intoxicação natural e experimental por Metternichia princeps (Solanaceae) em caprinos. Pesq. Vet. Bras. 32(9):903-911.

Stockham S.L. \& Scott M.A. 2011. Cálcio, fósforo, magnésio e seus hormônios reguladores, p.496-532. In: Ibid. (Eds), Fundamentos de Patologia Clínica Veterinária. Guanabara Koogan, Rio de Janeiro.

Thrall M.A. 2006. Diagóstico laboratorial da lesão muscular, p.391-393. In: Ibid. (Ed.), Hematologia e Bioquímica Clínica Veterinária. Roca, São Paulo. 